\title{
A Study of the Scrum Master's Role
}

\author{
John Noll ${ }^{1}$, Mohammad Abdur Razzak ${ }^{2}$, Julian M Bass ${ }^{3}$, and Sarah Beecham ${ }^{2}$ \\ ${ }^{1}$ University of East London, University Way, London, E16 2RD, UK \\ j.noll@uel.ac.uk \\ ${ }^{2}$ Lero, the Irish Software Research Centre, University of Limerick, Ireland \\ \{abdur.razzak, sarah.beecham\}@lero.ie \\ 3 University of Salford, The Crescent, Salford, M5 4WT, UK \\ j.bassesalford.ac.uk
}

\begin{abstract}
Scrum is an increasingly common approach to software development adopted by organizations around the world. However, as organizations transition from traditional plan-driven development to agile development with Scrum, the question arises as to which Scrum role (Product Owner, Scrum Master, or Scrum Team Member) corresponds to a Project Manager, or conversely which Scrum role should the Project Managers adopt?

In an attempt to answer this question, we adopted a mixed-method research approach comprising a systematic literature review and embedded case study of a commercial software development team. Our research has identified activities that comprise the Scrum Master role, and which additional roles are actually performed by Scrum Masters in practice.

We found nine activities that are performed by Scrum Masters. In addition, we found that Scrum Masters also perform other roles, most importantly as Project Managers. This latter situation results in tension and conflict of interest that could have a negative impact on the performance of the team as a whole.

These results point to the need to re-assess the role of Project Managers in organizations that adopt Scrum as a development approach. We hypothesize that it might be better for Project Managers to become Product Owners, as aspects of this latter role are more consistent with the traditional responsibilities of a Project Manager.
\end{abstract}

Key words: Agile software development, Scrum, Scrum Master role, Empirical Software Engineering

\section{Introduction}

Scrum $[1,2]$ is an increasingly common approach to software development adopted by organizations around the world. According to the annual State of Agile Survey [3], 94\% of organizations surveyed practice agile development.

However, while the vast majority of organizations practice some form of agile development, for most of these organizations, fewer than half of their teams have adopted agile methods [3]. Therefore, as organizations transition from traditional plan-driven development to agile development with Scrum, the question arises as to which Scrum role (Product Owner, Scrum Master, or Scrum Team Member) is the Project Manager, or conversely which Scrum role should Project Managers adopt? 
In an attempt to answer this question, we used a mixed method research approach comprising a systematic literature review and an embedded case study in a commercial software development organization. Firstly, we reviewed the literature on agile software development in order to identify which activities are conventionally performed by Scrum Masters. We the $\mathrm{n}$ conducted observations and practitioner interviews in order find out which activities are actually performed and which additional roles Scrum Masters perform.

We found nine activities that are performed by Scrum Masters. Of these, only three are conventional Scrum Master activities. Others would traditionally be considered the responsibility of the Product Owner or Scrum Team. In addition, we found that Scrum Masters also double in other roles, most importantly as Project Managers. This latter situation results in tension and conflict of interest that could have a negative impact on the performance of the team as a whole.

These results point to the need to re-assess the role of Project Managers in organizations that adopt Scrum as a development approach. We hypothesize that it might be better for Project Managers to become Product Owners, as this latter role is more consistent with the traditional responsibilities of a Project Manager.

The rest of this paper is organized as follows: in the next section, we present the background related to Scrum and Scrum roles. Next, we describe our research method. Following that, in Section 4 we present our results, and a discussion of those results in Section 5. Section 7 ends with our conclusions.

\section{Background}

There are three key roles defined in the Scrum development approach: the self-organizing development Scrum Team, the Scrum Master, and the Product Owner [2]. The Product Owner represents the external stakeholder interests (customer, users, product management) and so is the primary interface between these stakeholders and the software development team [4]. The Scrum Team is responsible for the actual software development. A further role, Product Manager, who "defines initial content and timing of the release, then manages their evolution as the project progresses and variables change... [and] deals with backlog, risk, and release content" was also described in the original description of Scrum [1]; this role is mostly performed by the Product Owner in modern descriptions of Scrum [5].

The Scrum Master is responsible for facilitating the development process, ensuring that the team uses the full range of appropriate agile values, practices and rules. The Scrum Master conducts daily coordination meetings and removes any impediments that the team encounters [2]. Six Scrum Master activities have been identified in a largescale distributed organisational context: process anchor, stand-up facilitator, impediment remover, sprint planner, scrum of scrums facilitator and integration anchor [6]. The process anchor nurtures adherence to agile methods. The stand-up facilitator ensures that team members share status and impediment information during each sprint. The impediment remover ensures developers can make progress with their work. The sprint planner supports the user story triage and workload planning that occurs prior to development work starting in each sprint. The scrum of scrums facilitator coordinates 
work with the other scrum masters in the development program. The integration anchor facilitates the merging of code bases developed by cooperating teams working in parallel.

According to Schwaber and Sutherland's scrum guidelines, "the Scrum Master is a servant-leader for the Scrum Team. The Scrum Master helps those outside the Scrum Team understand which of their interactions with the Scrum Team are helpful and which aren't. The Scrum Master helps everyone change these interactions to maximize the value created by the Scrum Team" [7]; in summary, the Scrum Master serves the development team. This is in contrast to the Product Owner, who is responsible for maximizing the value of the product and the work of the Scrum Team. Schwaber and Sutherland [7] state that although there is great flexibility in how this is achieved, the Product Owner is the sole person responsible for managing the Product Backlog.

According to Schwaber and Sutherland [7], Product Backlog management tasks include: 1. "ordering the items in the Product Backlog to best achieve goals and missions; 2. optimizing the value of the work the Development Team performs; 3. ensuring that the Product Backlog is visible, transparent, and clear to all, and shows what the Scrum Team will work on next; and, 4. ensuring the Development Team understands items in the Product Backlog to the level needed. [7]"

Evidence from practice shows that the Scrum Master role is evolving. For example, the role is sometimes shared, and activities performed by the Scrum Master are varied and somewhat different from the original vision. This was observed by Gupta et al [8], who found that the challenges of adapting scrum in a globally distributed team were helped by more than one person sharing the Scrum Master and Product Owner roles. Gupta et al developed a new Scrum Master taxonomy in which three new roles were created to reflect the complexity involved in managing a global software development team, and transitioning from Waterfall to scrum, the roles were: Scrum Master cum Part Product Owner (where development leads were also acting in part as product owners), Bi-Scrum Master (where a development leads worked remotely with the development team) and Chief Scrum Master (fulfilling the need to co-ordinate among scrum teams).

According to the ISO/IEC/IEEE standard on user documentation in agile [9] the Scrum Master and Product Manager have similar responsibilities when it comes to explaining changing or new requirements. "The scrum master and information development lead or project manager should provide guidance to the technical writers and other members of the agile development teams on how to handle changing or new requirements." Perhaps this conflating of roles is largely due to organizations converting the traditional project manager role to a scrum master role, "As more and more of our Project Managers become Scrum Masters and the Portfolio Managers becomes the Group Scrum Master, our Portfolio Management Office needed to become Agile itself [10]."

Adapting Scrum roles and creating new roles to manage large scale projects is observed in other studies, where an 'Area Product Owner' (APO) role was created; this APO role was shared by two people: a system architect and a product management representative. The system architect worked closely with the team, while the product management representative did not interact directly with the teams [11]. This combined role (shared between two people) worked well for this organisation and was reported as 
one of the successes of the project. However, in a later study, the same authors noted that line managers had a double role: that of Scrum Master, and that of traditional line management duties involving personnel issues such as performance evaluation. Over use of the Scrum Master role, who acted as a team representative at common meetings rather than rotate the role, was found problematic. The team felt that these meetings were a waste of time, and sent the scrum master instead of taking turns [12]. The frequent meetings in Scrum were also a problem in [13]. A scrum master's role is to facilitate daily coordination meetings where coordination meetings are used to communicate status of development work within the team and to product owners. However, the efficacy of daily coordination meetings was often compromised by too many stakeholders attending, or because the meetings were held too frequently to be beneficial for attendees [13].

Corrupting the careful balance between Scrum roles leads to other problems. For example Moe et al [14] observed that the scrum master also did estimates and did not involve all the team in discussing a task. This lead to developers working alone, poor team cohesion, and problems emerging at the end of the sprint rather than at the beginning. A lack of thorough discussion was said to reduce the validity of the common backlog "making the developers focus more on their own plan. Since the planning had weaknesses and none of the developers felt they had the total overview, this probably was one of the reasons for design-problems discovered later."

Yet, in a recent survey that looked into whether project managers still exist in agile development teams, Shashtri and Hoda were surprised to learn that $67 \%$ of organisations surveyed reported that they still had the Project Manager role. These authors call for more research into why the Project Manager continues to be present on agile software development projects, and how their role may have changed [15]. Conventional wisdom suggests that Project Managers use a command and control style of management, whereas Scrum Masters focus on leading and coaching [16]. As such, Scrum masters are not line managers for their sprint team members. Further, scrum masters do not assign work items to the members of their team, since the teams are self-organising [6].

In summary, there is an emerging theme in the literature, namely that the original balance of scrum master, product owner and team roles are being adapted, conflated, and possibly corrupted, to suit the needs of organizations transitioning from waterfall to Scrum, or scaling Scrum to large scale organisations. The extent to which the scrum master role has changed is unknown. Therefore, in this study we now look to the wider literature, and specifically ask two questions:

RQ1: What activities do scrum masters perform according to the empirical literature?

RQ2: What other roles do scrum masters perform in practice?

We ask these questions in order to establish a broader understanding of a key scrum role that has clearly evolved since its inception in 1995 [17] and later refinement [7], and consider whether adapting the theory proposed by Schwaber, Sutherland and Beedle is something to be embraced or resisted. 


\section{Method}

In order to address our research questions, we adopted a mixed method approach comprising a systematic literature review and an embedded case study of a commercial software development team [18]. We performed a systematic literature review [19] to identify the set of activities and additional roles performed by Scrum Masters. Then, using observations and transcripts of semi-structured interviews we undertook as part of an empirical study, we attempted to identify benefits or issues related to these activities and roles.

\subsection{Systematic Literature Review}

Our review of the literature was conducted in four steps.

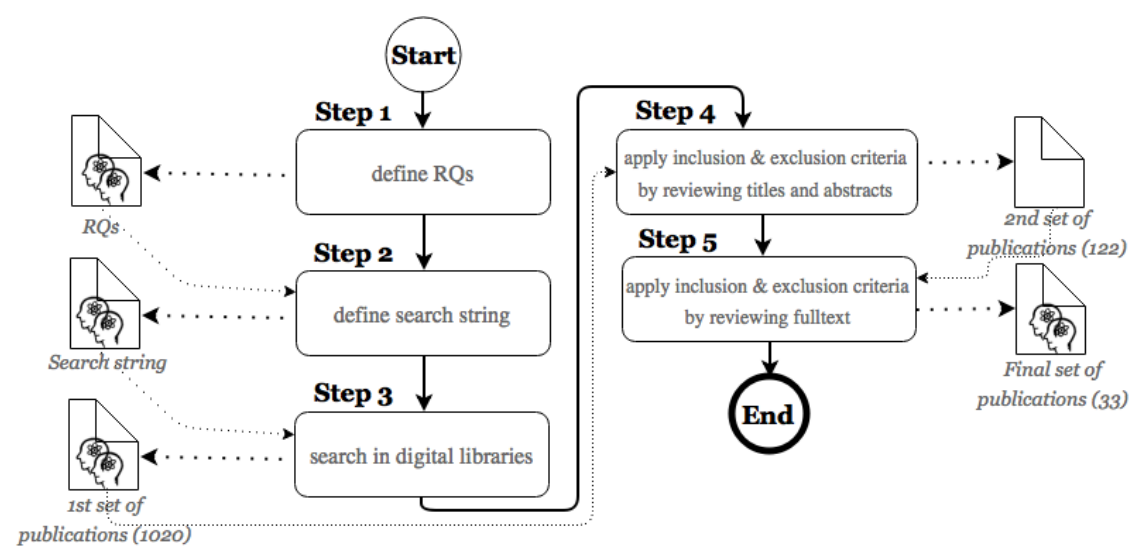

Fig. 1. Systematic literature review process

First, we defined two research questions:

1. What are the activities a Scrum Master performs?

2. What roles does the Scrum Master perform in addition to the Scrum Master role?

For expediency, we ran one search that combined both our research questions using the following search string (or variants of the search string to fit the various databases):

(activit* OR task* OR responsibilit* OR action* OR role* OR job*) AND ("Scrum Master")

We searched five well-established digital libraries listed in Table 1 for potentially relevant publications. This search yielded 1,020 candidate publications.

Subsequently, we applied inclusion and exclusion criteria (see Table 2) to the titles and abstracts of the initial set of 1,020 publications; this yielded a refined set of 122 publications. We again applied the inclusion and exclusion criteria to the full-text of these 122 publications, resulting in a final set of 33 publications. 
Table 1. List of databases and number of publications.

\begin{tabular}{lc}
\hline Database & \# of publications \\
\hline IEEEXplore & 13 \\
ACM Digital library & 378 \\
Scopus & 30 \\
Elesevier Science Direct & 282 \\
SpringerLink & 317 \\
\hline Total & $\mathbf{1 0 2 0}$ \\
\hline
\end{tabular}

Table 2. Inclusion and Exclusion criteria.

\begin{tabular}{|c|c|}
\hline Inclusion criteria & Exclusion criteria \\
\hline $\begin{array}{l}\text { IC1: Publication year: 2006-2017 } \\
\text { IC2: Language: English }\end{array}$ & $\begin{array}{l}\text { EC1: Is an experience report, book, presen- } \\
\text { tation, or blog entry }\end{array}$ \\
\hline $\begin{array}{l}\text { IC3: Full text available and acces- } \\
\text { sible }\end{array}$ & $\begin{array}{l}\text { EC2: Is a duplicated study (where authors } \\
\text { report similar results in two or more }\end{array}$ \\
\hline $\begin{array}{l}\text { IC4: Focus on Scrum, in the field } \\
\text { of software engineering }\end{array}$ & $\begin{array}{l}\text { publications-e.g. a journal paper that } \\
\text { is an extension of a conference paper); }\end{array}$ \\
\hline IC5: Peer reviewed work & exclude the least detailed paper, or if \\
\hline $\begin{array}{l}\text { IC6: Answers one or more of the } \\
\text { research questions }\end{array}$ & $\begin{array}{l}\text { unclear include the paper that is pub- } \\
\text { lished in the more notable venue. }\end{array}$ \\
\hline
\end{tabular}

Finally, from this final set of 33 publications, we extracted a list of Scrum Master's activities and additional roles, which are reported in Section 4.

\subsection{Embedded Case Study}

The company we studied, which we will call PracMed, is a medium-sized Irish-based software company that develops practice and lab management software for the optical industry.

Research Site PracMed employs approximately seventy staff members in its software development organization, including support and management staff. PracMed's annual sales approach $€ 20$ million, from customers across the British Isles, continental Europe, Scandinavia, North America and China.

Our study focused on TeamA, who are responsible for tailoring the company's product for a large customer in North America. The members of TeamA are distributed over four countries on two continents, with up to eight hours difference in timezones between locations. They are using Scrum to develop their software, with two weekly sprints. Table 3 shows the distribution of team members; of these, two team members share the Product Owner role, five are developers, one is the QA/Test lead, and one is Project Manager. In TeamA, the Project Manager also plays role of Scrum Master. Also, the Product Owners report to the Product Manager, who is based in Spain and is responsible for the strategic direction of the product. 
Table 3. Team Distribution.

\begin{tabular}{llc} 
Country & Agile Roles & No of Team Members \\
\hline \multirow{2}{*}{ Ireland } & Product Owner & 1 \\
& Software Developer & 3 \\
& Quality Assurance & 1 \\
\hline \multirow{2}{*}{ Canada } & Scrum Master (Project Manager) & 1 \\
& Product Owner & 1 \\
& Software Developer & 1 \\
\hline USA & Technical Lead (Software Developer) & 1 \\
\hline Spain & Product Manager & 1 \\
\hline
\end{tabular}

Data Collection We observed TeamA from January, 2016 through to March, 2017. Specifically, one of the authors observed approximately 200 of TeamA's Scrum ceremonies, including daily standups, sprint planning, backlog grooming, and sprint retrospectives. Due to team members being distributed across Europe and North America, the observations were made via video conference for each ceremony. The same author also conducted semi-structured interviews of each member of TeamA, which were recorded and transcribed. The interviews took approximately one hour, and resulted in 136 pages of transcribed verbatim data. The interview protocol is available from [20].

The observer also made contemporaneous hand-written notes during both the ceremony observations and interviews. Finally, the interviewer summarized the interviews using a mind-map, and presented the result to five interviewees in an online workshop to validate the insights gained from the interviews.

Data Analysis Interview recordings and transcripts were carefully reviewed. An open coding approach was used to identify topics in interview transcripts and contemporaneous notes of ceremonies. An approach informed by thematic analysis was used to group codes into concepts [21].

\section{Findings}

In this section we summarise our results and in response to our research questions, describe each of the Scrum Master's activities identified in our data analysis. As noted in our method, for consistency, where possible we adopt the activity name given in the literature.

\subsection{Systematic Literature Review}

Our paper selection process identified a total of 33 publications that fit our search and inclusion criteria (Table 4). 
Table 4. Publication by year.

\begin{tabular}{lcccccccccccc}
\hline Year & 2006 & 2008 & 2009 & 2010 & 2011 & 2012 & 2013 & 2014 & 2015 & 2016 & 2017 & Total \\
\hline Publications & 1 & 1 & 1 & 3 & 4 & 4 & 1 & 8 & 2 & 6 & 2 & 33 \\
\hline
\end{tabular}

Table 5. Scrum Master activities.

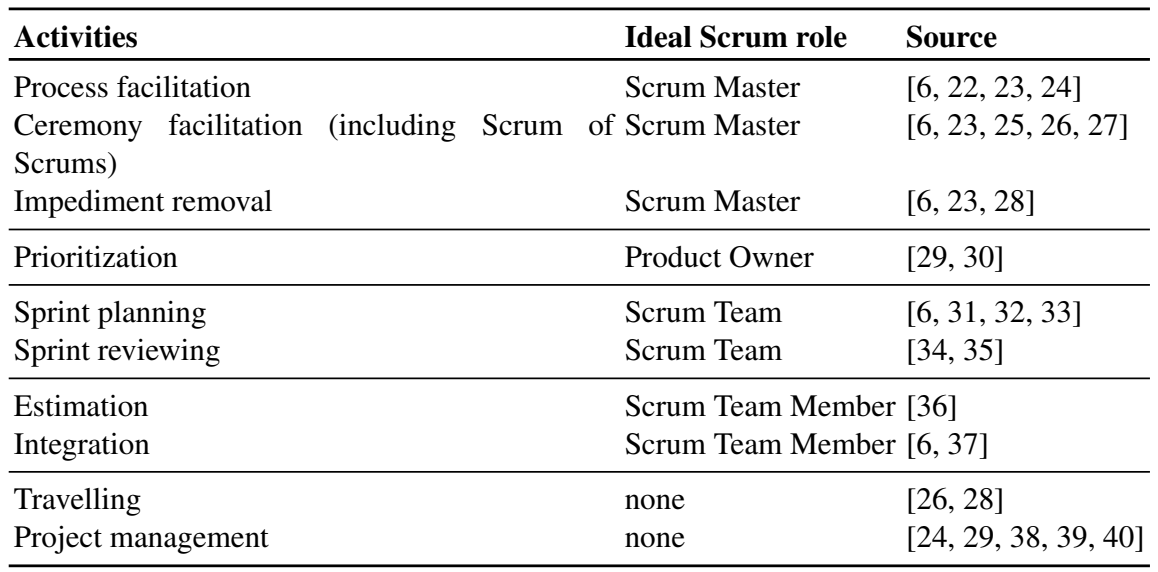

Activities From these papers, we identified nine activities performed by Scrum Masters; these are shown in Table 5. These activities are defined as follows:

Process facilitation involves guiding the Scrum Team on how to use Scrum to achieve their objectives.

Ceremony facilitation involves moderation of the daily scrum, backlog grooming, sprint planning, and sprint retrospective meetings that occur during each sprint.

Impediment removal is part of the Scrum Master as "servant manager" role: the Scrum Master serves as a buffer between the Scrum Team and external pressures, and also attempts to secure resources or remove blockers to progress that come from outside the team.

Prioritization involves ordering stories on the product and sprint backlogs by order of importance.

Sprint planning identifies those stories on the product backlog that will fit into a single sprint, taking into account team velocity and capacity, and story estimates.

Sprint reviewing is part of the Sprint Retrospective ceremony where the team identifies what went well, what could be improved, and might be added or removed from their process to be more effective.

Estimation assigns a value in "story points" or ideal engineering time representing the effort required to complete a story.

Travelling is an activity associated with distributed teams that involves visiting different sites where teams are located, to facilitate communications [41]

Project management is a traditional management activity found in waterfall-style development projects. 
Roles Fifteen papers mentioned other roles that Scrum Masters hold in addition to that of Scrum Master. These are summarized in Table 6.

Table 6. Scrum Master additional roles.

\begin{tabular}{lcc}
\hline Role & Company-size & Source \\
\hline Project Manager & Large-scale & {$[42,43,44,45,46]$} \\
Product Owner & unclear & {$[29,44]$} \\
Architect/Software Designer & Large-scale & {$[47,48]$} \\
Project Lead & Large-scale & {$[49]$} \\
Developer/Senior Engineer & Large-scale & {$[30,43,49,50,51]$} \\
Team Leader & Large-scale & {$[42,49,52]$} \\
Test Lead & unclear & {$[43]$} \\
Head of Department/Dir. of Eng/Dev. Mgr. & Large-scale & {$[30,43,53,54]$} \\
\hline
\end{tabular}

Of these eight roles, four (Architect/Software Designer, Developer/Senior Engineer, Team Leader, and Test Lead) would be considered technical roles, and three (Project Manager, Project Lead, Head of Department) are management roles. In total, nine of fifteen papers reported the Scrum Master also taking on some kind of management role, with six explicitly mentioning "Project Manager" or "Project Lead."

\subsection{Embedded Case Study}

We observed this tension and conflict of interest in our case study organization. On the one hand, the Scrum Master performs project management duties:

So, we do all the traditional project management roles as in doing the scope statement, the planning, change control process, communication management plan and all that stuff. And, then internally [we act as] Scrum Master.

The planning part of this role has a waterfall characteristic:

When I got to start working on this project when there was a contract - there is a very specific set of requirements. An analysis document is attached to that contract. And there is a very specific set of actual deliverables ... these are actual things that we need to build and are doing. Umm, there is a very specific budget for example, and the timeline is normally set as well in a high level. You know it's a one year project or six months. Then we get started and we start with working with them then we create a scope statement, we create a brief we you know create a charter [that] depends on the size of the project and really how much of this spec we need to do.

In PracMed, project management for projects involving customization for large accounts also involves interfacing with the customer:

So, remember with the client we got, the client facing role is the Project Manager. 
... let's say I have both roles. Project manager is when I am dealing with our clients and [customer] would be a great example.

The Scrum Master admits balancing these two roles creates tension:

... Madness! It's hard. ... if you know about one role not the other, I think it's easier because you do the best you can in your Scrum Master role or you do the best in your Project Manager role ignoring the other. Now, the dilemma is as a Project Manager I still know what the Scrum Master role is, I know the Agile team - I know I am not supposed to break their rules and let them be self-organizing and do all of that. At the end you have the client to answer [to], you have management to answer to. So, you can't just say oh well it's in the sprint or they plan for it or I don't know when its gonna get done because team is self-organizing. So, I think that's why the challenges come. So, you have responsibilities but yet you don't have full on.

In particular, there is tension between the Project Manager as customer interface, and the Scrum Master role:

...Yah, pressure will always be there ... you cannot avoid that but it's about cause and effect type of thing I guess. An example would be, the client would want to know a plan ... they want to have a plan for everything that we are going to do. Lets say, there are five change requests for example that's in the progress as we are still talking to them about what the requirement is. So, there is no estimate on this. They want to know exactly when all are going to get done. Now, in a Agile world there is no way that I could tell them when they are going to get done until the estimates are there, until we started a sprint planning, we don't know this will go into this sprint or not, product owner needs to be prioritize the things and product owner has other five epics on the top list ... so things like that which is very challenging and obviously with a client it's hard because I cannot just tell them we are doing Agile. So, it won't work this way. After I come back internally and pressure the guys ...can you first track change request. Can you do the estimate on it. If they do, they are missing out something else they are supposed to do. So, I think that the main challenge is the client but not internally because we all know, we are the PracMed team, they know about it, they understand it. But, to the client it's hard to say and you cannot just say we are doing Agile. So, you have to wait till the next planning or when there is a release plan. But, they want to know every detail ... they want to know every task, when it gets done then you can test it.

\section{Discussion}

Scrum defines only three roles: Product Owner, Scrum Team Member, and Scrum Master [2]. This results in a balance between the customer, user, and other stakeholder interests, which are represented by the Product Owner, and the technical realities of 
software development, which are represented by the Scrum Team. The Scrum Master facilitates the interaction between these two interests, and also serves to insulate the team as a whole from external distractions (hence the description "servant-leader" that is often used to describe Scrum Masters [5]).

Three Scrum Master activities (Process facilitation, Ceremony facilitation, and Impediment removal) that formed part of our nine activities observed from the literature would be considered "traditional" Scrum Master activities, as defined by Schwaber and Beedle [2]. Prioritizing, on the other hand, is supposed to be the responsibility of the Product Owner, and Estimation is supposed to be performed by the Scrum Team members [2]. While the Scrum Master may facilitate these activities, he or she is not supposed to perform them; this is because Scrum relies on a balance of power between "business" and "technical" interests in order to set realistic sprint goals [2, 55]. Given the Scrum Master's role as facilitator, and mediator between the Product Owner and the Scrum Team, overloading the Scrum Master role with project management introduces a conflict of interest that can compromise the Scrum Master's ability to ensure a balance between the interests of external stakeholders and the Scrum Team: the Scrum Master is supposed to insulate the team and remove impediments, but as Project Manager, he or she would also have responsibilities to achieve objectives set by higher levels of the organization. Stray and colleagues observed that when the Scrum Master is viewed as a manager rather than facilitator, the daily scrum becomes a management reporting exercise rather than a team communication meeting [13].

\subsection{The Way Ahead}

If tensions are created when the Scrum Master activities are combined with Project Manager activities, which Scrum role is the right role to perform Project Manager activities?

To answer this question, it's useful to consider what project management involves in Scrum, especially considering Scrum teams are supposed to be "self organizing." Schwaber defines five project management activities that must be carried out when undertaking development using the Scrum approach:

1. Vision management - establishing, nurturing, and communicating the product vision.

2. ROI management - monitoring the project's progress against Return on Investment goals, including updating and prioritizing the product backlog to reflect these goals.

3. Development iteration management - expanding items on the Product Backlog into items for the Sprint Backlog, then implementing those items in order of priority.

4. Process management - facilitating ceremonies, removing impediments, and shielding the team from outside interference.

5. Release management - deciding when to create an official release, in response to market pressures and other investment realities.

Of these, only Process management is the responsibility of the Scrum Master; Development iteration management is the responsibility of the development team, and the remaining activities (Vision management, ROI management, and Release management) are the Product Owner's responsibility. 
This suggests that, when organizations decide to adopt Scrum, their existing Project Manager's should be assigned to the Product Owner role. The advantages are twofold: first, as Product Owners, First, Project Managers could advocate for business requirements without feeling tension with their Product Owner responsibilities, since such advocacy is consistent with the Product Owner role.

Second, the Scrum Master would be free to support the Scrum Team when business requirements conflict with technical reality, and to support the Product Owner when business priorities differ from Scrum Team Member preferences (for example, when certain mundane functionality must be developed to keep the product roadmap progressing, at the expense of more technically interesting features), and to support both when upper management pressure threatens to override or compromise the team's own decisions.

Our insights into the tensions and conflicts created by combining the Scrum Master and Project Manager roles are based on observations of a single development team and interviews of one Scrum Master/Project Manager. As such, we must be extremely cautious about generalizing our results. However, our observations do suggest two propositions that can serve as the basis for further research:

P1: When adopting Scrum, teams will be more successful if the former Project Manager adopts the Product Owner role rather than the Scrum Master role.

Conversely,

P2: When adopting Scrum, teams that combine the Scrum Master and Project Manager roles will experience tension resulting from the conflict of interests between these two roles.

\section{Limitations}

This research adopts a mixed method approach to compensate for the weaknesses of each research approach used in isolation. Practitioner roles, such as that of scrum master, are rapidly evolving over time and hence while literature is important it cannot be solely relied upon for an up-to-date perspective. On the other hand, an empirical case study conducted without recourse to previous literature would be weakened. Hence this paper combines a systematic literature review with an empirical embedded case study in a mixed method approach.

\section{Conclusions}

In this study, we adopted a mixed method research approach to investigate First, we performed a systematic literature review related to the Scrum Master role and then an embedded case study to uncover empirical evidence of what activities Scrum Master's actually perform, and what additional roles they take on. We found nine activities that are performed by Scrum Masters, and eight additional roles that Scrum Masters also play.

Combining the findings from literature with observations from a case study of a medium-sized development organization, we identified tensions and conflicts between 
the Scrum Master role and the Project Manager role that are often combined in practice. As such, we hypothesize that, when adopting Scrum, organizations should appoint existing Project Managers to the Product Owner role, rather than making them Scrum Masters.

\section{Acknowledgments}

We thank the members of TeamA and members of the Project Management Team for their generous and thoughtful collaboration on this study, and PracMed, for allowing us to study their software development efforts. This work was supported, in part, by Science Foundation Ireland grants 10/CE/I1855 and 13/RC/2094 to Lero - the Irish Software Research Centre (www. lero. ie).

\section{References}

[1] Schwaber, K.: SCRUM development process. In Sutherland, J., Casanave, C., Miller, J., Patel, P., Hollowell, G., eds.: Business Object Design and Implementation, OOPSLA '95 Workshop Proceedings, Springer-Verlag London (October 1995) 117-134

[2] Schwaber, K., Beedle, M.: Agile software development with Scrum. Volume 1. Prentice Hall Upper Saddle River (2002)

[3] VERSIONONE.COM: 11th annual state of agile ${ }^{\mathrm{TM}}$ survey. Technical report, VersionOne, Inc (2017)

[4] Schwaber, K.: Agile project management with Scrum. Microsoft press (2004)

[5] Cohn, M., Schwaber, K.: The need for agile project management. Agile Times 1 (January 2003)

[6] Bass, J.M.: Scrum master activities: process tailoring in large enterprise projects. In: Global Software Engineering (ICGSE), 2014 IEEE 9th International Conference on, IEEE (2014) 6-15

[7] Schwaber, K., Sutherland, J.: The Scrum guide-the definitive guide to Scrum: The rules of the game, july 2011. Available on-line at: http: / / www. scrum.org/ storage/scrumguides/Scrum \ะ20Guide (2016)

[8] Gupta, R.K., Reddy, P.M.: Adapting agile in a globally distributed software development. In: 2016 49th Hawaii International Conference on System Sciences (HICSS). (Jan 2016) 5360-5367

[9] ISO/IEC/IEEE: Systems and software engineering - developing user documentation in an agile environment. Technical report, International Standards Organization (March 2012)

[10] Tengshe, A., Noble, S.: Establishing the Agile PMO: Managing variability across projects and portfolios. In: Agile 2007 (AGILE 2007). (Aug 2007) 188-193

[11] Paasivaara, M., Lassenius, C.: Scaling Scrum in a large distributed project. In: 2011 International Symposium on Empirical Software Engineering and Measurement. (Sept 2011) 363-367 
[12] Paasivaara, M., Lassenius, C.: Scaling Scrum in a large globally distributed organization: A case study. In: 2016 IEEE 11th International Conference on Global Software Engineering (ICGSE). (Aug 2016) 74-83

[13] Stray, V.G., Lindsjorn, Y., Sjoberg, D.I.: Obstacles to efficient daily meetings in agile development projects: A case study. In: Empirical Software Engineering and Measurement, 2013 ACM/IEEE International Symposium on, IEEE (2013) $95-102$

[14] Moe, N.B., Dingsyr, T., Dyb, T.: Understanding self-organizing teams in agile software development. In: 19th Australian Conference on Software Engineering (aswec 2008). (March 2008) 76-85

[15] Shastri, Y., Hoda, R., Amor, R.: Does the project manager still exist in agile software development projects? In: 2016 23rd Asia-Pacific Software Engineering Conference (APSEC). (Dec 2016) 57-64

[16] Berczuk, S., Lv, Y.: We're all in this together. IEEE Software 27(6) (2010) 12-15

[17] Sutherland, J.V., Schwaber, K.: Business object design and implementation: Oopsla'95 workshop proceedings. the university of michigan. Technical report, ISBN 3-540-76096-2 (1995)

[18] Creswell, J.W.: Research Design: Qualitative, Quantitative, and Mixed Methods Approaches. Fourth edn. SAGE Publications, Inc, Thousand Oaks, California (2013)

[19] Kitchenham, B., Charters, S.: Guidelines for performing systematic literature reviews in software engineering, v. 2.3. Technical Report EBSE-2007-01, Software Engineering Group, School of Computer Science and Mathematics, Keele University (2007)

[20] Beecham, S., Noll, J., Razzak, M.A.: Lean global project interview protocol. Available at http://www.lero.ie/sites/default/files/ Lero_TR_2017_02_Beecham_Noll_Razzak-Lean\\%20Global\ $\div 20$ Project $\ \div 20$ Interview $\backslash \% 20$ Protocol.pdf (2017)

[21] Braun, V., Clarke, V.: Using thematic analysis in psychology. Qualitative Research in Psychology 3(2) (January 2006) 77-101

[22] Andriyani, Y., Hoda, R., Amor, R.: Reflection in agile retrospectives. In: International Conference on Agile Software Development, Springer (2017) 3-19

[23] Baumgart, R., Hummel, M., Holten, R.: Personality traits of Scrum roles in agile software development teams-a qualitative analysis. In: ECIS. (2015)

[24] Costa, N., Santos, N., Ferreira, N., Machado, R.J.: Delivering user stories for implementing logical software architectures by multiple Scrum teams. In: International Conference on Computational Science and Its Applications, Springer (2014) 747-762

[25] Dorairaj, S., Noble, J., Malik, P.: Understanding team dynamics in distributed agile software development. In: International Conference on Agile Software Development, Springer (2012) 47-61

[26] Alzoubi, Y.I., Gill, A.Q., Al-Ani, A.: Empirical studies of geographically distributed agile development communication challenges: A systematic review. Information \& Management 53(1) (2016) 22-37 
[27] Maranzato, R.P., Neubert, M., Herculano, P.: Moving back to Scrum and scaling to Scrum of scrums in less than one year. In: Proceedings of the ACM international conference companion on Object oriented programming systems languages and applications companion, ACM (2011) 125-130

[28] Bless, M.: Distributed meetings in distributed teams. In: International Conference on Agile Software Development, Springer (2010) 251-260

[29] Cajander, Å., Larusdottir, M., Gulliksen, J.: Existing but not explicit-the user perspective in Scrum projects in practice. In: IFIP Conference on Human-Computer Interaction, Springer (2013) 762-779

[30] Stray, V.G., Moe, N.B., Dingsøyr, T.: Challenges to teamwork: a multiple case study of two agile teams. In: International Conference on Agile Software Development, Springer (2011) 146-161

[31] Drury, M., Conboy, K., Power, K.: Obstacles to decision making in agile software development teams. Journal of Systems and Software 85(6) (2012) 1239-1254

[32] Heikkilä, V.T., Paasivaara, M., Rautiainen, K., Lassenius, C., Toivola, T., Järvinen, J.: Operational release planning in large-scale Scrum with multiple stakeholders-a longitudinal case study at f-secure corporation. Information and Software Technology 57 (2015) 116-140

[33] Vlietland, J., van Vliet, H.: Towards a governance framework for chains of Scrum teams. Information and Software Technology 57 (2015) 52-65

[34] Chamberlain, S., Sharp, H., Maiden, N.: Towards a framework for integrating agile development and user-centred design. In: International Conference on Extreme Programming and Agile Processes in Software Engineering, Springer (2006) 143153

[35] Stray, V., Fægri, T.E., Moe, N.B.: Exploring norms in agile software teams. In: Product-Focused Software Process Improvement: 17th International Conference, PROFES 2016, Trondheim, Norway, November 22-24, 2016, Proceedings 17, Springer (2016) 458-467

[36] Daneva, M., Van Der Veen, E., Amrit, C., Ghaisas, S., Sikkel, K., Kumar, R., Ajmeri, N., Ramteerthkar, U., Wieringa, R.: Agile requirements prioritization in large-scale outsourced system projects: An empirical study. Journal of systems and software 86(5) (2013) 1333-1353

[37] Alaa, G., Samir, Z.: A multi-faceted roadmap of requirements traceability types adoption in Scrum: an empirical study. In: Informatics and Systems (INFOS), 2014 9th International Conference on, IEEE (2014) SW-1

[38] Baskerville, R., Pries-Heje, J., Madsen, S.: Post-agility: What follows a decade of agility? Information and Software Technology 53(5) (2011) 543-555

[39] Caballero, E., Calvo-Manzano, J.A., San Feliu, T.: Introducing Scrum in a very small enterprise: A productivity and quality analysis. In: European Conference on Software Process Improvement, Springer (2011) 215-224

[40] Santos, R., Flentge, F., Begin, M.E., Navarro, V.: Agile technical management of industrial contracts: Scrum development of ground segment software at the european space agency. In: International Conference on Agile Software Development, Springer (2011) 290-305 
[41] Bass, J.M.: How product owner teams scale agile methods to large distributed enterprises. Empirical Software Engineering 20(6) (2015) 1525 - 1557

[42] Gren, L., Torkar, R., Feldt, R.: Group development and group maturity when building agile teams: A qualitative and quantitative investigation at eight large companies. Journal of Systems and Software 124 (2017) 104-119

[43] Hoda, R., Murugesan, L.K.: Multi-level agile project management challenges: A self-organizing team perspective. Journal of Systems and Software 117 (2016) 245-257

[44] Tuomikoski, J., Tervonen, I.: Absorbing software testing into the Scrum method. In: International Conference on Product-Focused Software Process Improvement, Springer (2009) 199-215

[45] Stray, V., Sjøberg, D.I., Dybå, T.: The daily stand-up meeting: A grounded theory study. Journal of Systems and Software 114 (2016) 101-124

[46] Moe, N.B., Dingsøyr, T.: Scrum and team effectiveness: Theory and practice. In: International Conference on Agile Processes and Extreme Programming in Software Engineering, Springer (2008) 11-20

[47] Díaz, J., Pérez, J., Garbajosa, J.: Agile product-line architecting in practice: A case study in smart grids. Information and Software Technology 56(7) (2014) $727-748$

[48] Sekitoleko, N., Evbota, F., Knauss, E., Sandberg, A., Chaudron, M., Olsson, H.H.: Technical dependency challenges in large-scale agile software development. In: International Conference on Agile Software Development, Springer (2014) 46-61

[49] Diebold, P., Ostberg, J.P., Wagner, S., Zendler, U.: What do practitioners vary in using Scrum? In: International Conference on Agile Software Development, Springer (2015) 40-51

[50] Garbajosa, J., Yagüe, A., González, E.: Communication in agile global software development: An exploratory study. In: OTM Confederated International Conferences" On the Move to Meaningful Internet Systems", Springer (2014) 408-417

[51] Li, J., Moe, N.B., Dybå, T.: Transition from a plan-driven process to Scrum: a longitudinal case study on software quality. In: Proceedings of the 2010 ACMIEEE international symposium on empirical software engineering and measurement, ACM (2010) 13

[52] Galster, M., Angelov, S., Meesters, M., Diebold, P.: A multiple case study on the architect's role in Scrum. In: Product-Focused Software Process Improvement: 17th International Conference, PROFES 2016, Trondheim, Norway, November 22-24, 2016, Proceedings 17, Springer (2016) 432-447

[53] Alahyari, H., Svensson, R.B., Gorschek, T.: A study of value in agile software development organizations. Journal of Systems and Software 125 (2017) 271288

[54] Vlaanderen, K., van Stijn, P., Brinkkemper, S., van de Weerd, I.: Growing into agility: process implementation paths for Scrum. In: International Conference on Product Focused Software Process Improvement, Springer (2012) 116-130

[55] Leffingwell, D.: Scaling software agility: Best practices for large enterprises. Addison Wesley, Boston, MA, USA (2007) 